\title{
Парцеллированные предложения в современном русском и польском языках
}

Ключевые слова: парцелляция, главное предложение, парцеллят, русский язык, польский язык.

Key words: parcelling, main (basic) sentence, partcellator, Russian language, Polish language.

\begin{abstract}
The present article concentrates on different types of Russian and Polish parcelled constructions.

Parcelling is one of the expressive syntactic means and is defined as the division of the sentence structure into several intonation-separated parts. A parcelled construction consists of the basic (main) part, which is a structurally, syntactically and semantically independent sentence, and the partcellator - syntactically and semantically dependent on the main part. Parcelling occurs on the level of a simple sentence as well as on the level of a compound sentence. This phenomenon is used in order to select the most important information and to attract the addressee's attention.
\end{abstract}

Парцелляция как прием экспрессивного синтаксиса все чаще употребляется в современном русском и польском языках. В русских источниках она определяется как особый способ членения единой синтаксической структуры, т.е. предложения на две или несколько коммуникативно самостоятельных фраз [Rozental', Telenkova 2001; Ârceva 1990], например: Он [...] тоже пошел. В магазин. Сигарет купить (Шукшин). В речи описываемое явление осуществляется посредством интонации, а в письменном тексте ее графическими показателями являются знаки конца предложения, т.е. точка, многоточие, вопросительный и восклицательный знаки [Kopnina 2008; Skovorodnikov 1980], например:

Я? Вам? Дал телефон? Что за ерунда! - не понимая, сказал Никитин (Бондарев). 
Парцеллированная конструкция состоит из базовой (главной, основной) части и парцеллята (парцеллирующей части). Базовая часть - это структурная основа, организующая высказывание в структурное и смысловое целое вместе с парцеллятом. Структурно зависимая часть предложения, выделенная в самостоятельную фразу, называется парцеллятом [Babajceva 2000; Vannikov 1979; Kopnina 2008].

В польской лингвистической литературе нет термина parcelacja [Gołąb, Heinz, Polański 1968; Urbańczyk 1978; Polański 1993]. Однако он появляется в работах, в которых авторы ссылаются на русские источники или рассматривают парцеллированные предложения в русском языке. Например, Э. Коморовска в монографии, посвященной постпозитивной парентезе, обращает внимание на прием парцеллирования, который в некоторой степени относится с постпозитивной парентезой. В общем же предлагает для того типа выражений употребление термина из русской лингвистической литературы - парцелляция [Komorowska 2001]. Польские исследователи неоднократно занимались предложениями, в которых точка ставится перед тем, как оно заканчивается формально. Такое выделение точкой фрагмента предложения рассматривается как нарушение пунктуационной правильности, а также в работах касающихся экспрессивного синтаксиса [Jodłowski 1932; Saloni 1971, 1977; Pospiszylowa 1973; Angełowa 1985; Grzesiuk 1995]. Для названия этого явления употребляется термин usamodzielnianie zdania, а выделенный после точки фрагмент определяется как wyodrębniony interpunkcyjnie człon, usamodzielniony człon, usamodzielnione zdanie, człon wyodrębniony $w$ wypowiedzenie, samodzielny człon и usamodzielnienie.

Многие утверждают, что употребление парцеллированных предложений выполняет стилистическую функцию, выражает эмоции говорящего и отражает спонтанную, неподготовленную разговорную речь.

В русском и польском языках отдельные самостоятельные фразы, т.е. парцелляты, могут выделяться как члены простых, так и части сложных предложений. В настоящей статье описываются основные типы парцеллированных высказываний ${ }^{1}$.

1 Фактографический материал был отобран из следующих произведений в электронной версии:

Aksenov V., Ostrov Krym; Aksenov V., Skaži izûm; Balašov D., Marfa-posadnica; Barabašov V., A smert'podoždet; Vasil'ev B., A zori zdes'tihie...; Bigl' P., Arhaičeskie razvlečeniâ; Granovskij A., Vlastelinvidenij (Gibloe mesto - 6); Gurčenko L., Aplodismenty; Efremov I., Tais Afinskaâ; Il'âsov Â., Sogdiana; Il'f I., Petrov E., Zolotoj telenok; Il'f I., Petrov E., Odnoètažnaâ Amerika; Kornilaev P., Sozdannye dlâ Raâ; Medvedeva N., A u nih byla strast'; и печатных изданий: Akunin B., Tureckij gambit, Moskva 2004; Abdullaev Č., Počti neveroâtnoe ubijstvo, Moskva 1997; Abdullaev Č., Golubye angely, Moskva 1997; Doncova D., Biletna kover-vertolet, Moskva 2008; Brzezińska A., Pilipiuk A., Ziemkiewicz R.A., Zajdel 2003: Antologia. Wybór najlepszych opowiadań polskich autorów, Lublin 2003; Chmielewska J., Lesio, Warszawa 2010; Domagalik M., Wiśniewski J.L., 188 dni i nocy, Warszawa 2008; Głowacki J., Polowanie na muchy i inne 


\section{1. Парцелляция простого предложения}

Среди простых парцеллированных предложений можно выделить три основных типа конструкций, в которых:

a) в парцелляте повторяется тот же самый член предложения, который имеется в главной части, например:

А она подумала, что хотела бы, чтоб был и он, и Писатель. И Писатель, и Критик (Medvedeva).

Кроме них, никого на этаже не было. Не было! (Abdullaev)

Я смотрела на себя в зеркало и об этой женщине не знала ничего. Ничего (Gurčenko).

-Я все у тебя куплю! Все! Bсе! (Aksenov)

- Nie mam na to najmniejszej ochoty, ale obawiam się, że musimy. Tak mi nakazuje honor. Obowiazek wobec przyjaciela (Pilipiuk).

Projektant musiat na klęczkach przepraszać szejków. W końcu to oni kupuja dla haremów ciuchy haute couture. Oni i ruska mafia (Gretkowska).

Dopiero po pierwszej nocy, rok od pocalunku w parku, pierwszej prawdziwej nocy z nagościa, rozkosza i bezwstydem on powiedziat jej, że kochat ja bardziej, niż boi się kary. Jakiejkolwiek kary (Wiśniewski).

Повторение однородных членов предложения считается одним из простейших случаев парцелляции [Vannikov 1979]. Повторяющийся, парцеллированный элемент выступает обычно в функции актуализатора. Это могут быть те же самые слова нераспространенные или сопровождающиеся добавочной информацией, а также слова близкие по значению.

б) в главной части предложения отсутствует член, который подвергается парцелляции. Такой тип выступает только при отчленении

opowiadania, Warszawa 1977; Gretkowska M., Pietucha P., Sceny z życia pozamatżeńskiego, Warszawa 2003; Gretkowska M., Kobieta i mężczyźni, Warszawa 2007; Gretkowska M., Miłość po polsku, Warszawa 2010; Lem S., Bajki robotów, Warszawa 1983; Masłowska D., Wojna posko-ruska pod flaga biało-czerwona, Warszawa 2009; Pilipiuk A., OPERACJA Dzień Wskrzeszenia, Lublin 2006; Pilipiuk A., Dziedziczki, Lublin 2007; Pilipiuk A., Kroniki Jakuba Wędrowycza, Lublin 2007; Pilipiuk A., Oko Jelenia. Droga do Nidaros, Lublin 2008; Pilipiuk A., Oko Jelenia. Drewniana Twierdza, Lublin 2008; Pilipiuk A., Oko Jelenia. Srebrna Łania z Visby, Lublin 2008; Pilipiuk A., Oko Jelenia. Pan Wilków, Lublin 2009; Pilipiuk A., Rzeźnik drzew, Lublin 2009; Pilipiuk A., Oko Jelenia. Triumf lisa Reinicke, Lublin 2010; Pilipiuk A., Oko Jelenia. Sfera Armilarna, Lublin 2011; Szczeklik A., Katharsis. O uzdrowicielskiej mocy nauki i sztuki, Kraków 2003; Tokarczuk O., Szafa, Wałbrzych 1998; Tokarczuk O., Dom dzienny, dom nocny, Wałbrzych 1999; Wiśniewski J.L., Samotność w sieci, Warszawa 2001; Wiśniewski J.L., Zespoły napięć, Warszawa 2002; Wiśniewski J.L., Intymna teoria względności, Kraków 2005; Wiśniewski J.L., Molekuły emocji, Kraków 2006; Wiśniewski J.L., Arytmie, Warszawa 2008; Wiśniewski J.L., Bikini, Warszawa 2009. 
второстепенных членов предложения, т.е. дополнения, определения и обстоятельства. Как в русском, так и в польском языках нет текстов, в которых в базовой части не имеется сказуемое или подлежащее. Итак, в самостоятельную фразу выделяются:

- дополнения, например:

И вот она посмотрела на весь этот ужас и... ушла. С Критиком (Medvedeva).

Znali się z technikum. Podziwiat go od początku. Za ten jego mózg i tę wytrwatość (Wiśniewski).

- $\quad$ определения, например:

- А может макарончики сварить? Твои любимые итальянские гнезда «Макфа»? Я и соус могу к ним сделать. Грибной! (Doncova)

Einstein wybuchnąt śmiechem. Autentycznym i niepozowanym (Wiśniewski).

- обстоятельства, например:

Она засмеялась. Радостно, легко. Несколько раз повторила его имя, точно пробуя на вкус (Abdullaev).

- Вовсе нет! Пьттаюсь объяснить приниипы здорового питания. Для твоего же блага! (Донцова)

Brakowało mi tego. Tak bardzo (Wiśniewski).

Zatrzymałem się w pół kroku. Faktycznie stała tu zagroda. Kiedyś (Pilipiuk).

Вынесенные в парцеллят дополнения, определения и обстоятельства являются необязательными членами предложения. Автор решил добавить эти члены и выделить их, распространяя или нет, в самостоятельные фразы. Таким образом они стали самыми важными фрагментами высказывания, на которые обращается особое внимание читателя.

в) парцелляты выступают как члены ряда, т.е. первый член выступает в главной (базовой) части предложения, а следующие парцеллируются. Однородные члены в таких конструкциях связываются друг с другом посредством внутрирядных отношений разных типов:

- $\quad$ пояснения, при которых парцеллированный член конкретизирует значение соответствующего члена в базовой части, например:

Сын просил привезти новый пистолет. Игрушку (Abdullaev).

Znalazłam tam ustawione niedbale kamienne rzeźby. Rozumiem, że musiały się tutaj znaleźć. Na wygnaniu (Tokarczuk).

Русский парцеллят вносит очень важную информацию - раскрывает тип предмета, а в польском примере конкретизирует значение местоимения в главной части, указывающего на место.

- перечисления, описывающие некоторую совокупность объектов, но при этом каждый член ряда является значимым, и автор обращает на это внимание читателя, парцеллируя их, например: 
- Ага! Ты обманул меня! Обещал и бросил! Ну погоди! Я тебя убью! И Лизку тоже! (Doncova)

На улице, не на той, где жила Женщина, а за углом, было полно людей, покупаюших тонны еды. Везущих корзины на колесиках с едой, несущих корзины с едой на руке, как грибники. И местные активисты предлагали «Юманите», либо что-то про «зеленых», либо про социалистов. И все несли eдy (Medvedeva).

Mial zupetnie puste spojrzenie. Wypalone. Nieobecne. Potem powiedziano mi, że to emerytowany egzorcysta. Człowiek, który zobaczyt $w$ życiu zbyt wiele (Pilipiuk).

Ten dach jest zbyt gladki. Zbyt stromy. Zbyt śliski (Pilipiuk).

Выделение в самосоятельные фразы элементов группы каких-то объектов или признаков позволяет указать каждый из них индивидуально и притом удобно представить длинную, сложную конструкцию.

- $\quad$ градации, при которых значение члена предложения в базовой части является менее интенсивным, чем значение соответствующего члена в парцелляте, например:

И торчал большой нос. Огромный нос. Без этого носа Критик был похож на девочку. А с носом он был похож на девочку-уродку (Medvedeva).

To byto dla niej bardzo ważne. Najważniejsze (Wiśniewski).

Градация при добавочной парцелляции подчеркивает очень высокую степень признака.

- $\quad$ противительности, при которых значение парцеллированного члена противопоставляется значению соответствующего члена в базовой части, например:

Мы увидели цельй городок, с канализачией и водопроводом, с подведенным на все участки газом и электричеством, одним словом - город со всеми удобствами. Но без домов. Еще ни одного домика не было в этом городке, где улииам были даны даже названия (Il'f, Petrov).

Pod krzyżem duża metalowa tablica. Aby magnesem przypiać do tej tablicy swoje pożegnanie. A przy wejściu do kliniki, zaraz za automatycznymi drzwiami, jest inna tablica. Wcale nie magnetyczna. Zwykta korkowa. A na niej kolorowymi szpilkami przypięte sa kartki (Domagalik, Wiśniewski).

- $\quad$ альтернативы, выражаемые эксплицитно при помощи союза или/ albo:

- Заходите к нам с Валентиной в гости. Или отдыхать приезжайте. Море, всё-таки!... Телефон дать? (Barabašov)

- Stońce wędruje po nieboskłonie. Przesuwa się, zastaniając kolejno pewne gwiazdozbiory zodiaku. Obecnie jest w znaku Ryb. Astronom wyjaśnitby to pani lepiej. Albo astrolog (Pilipiuk). 
При отношениях градации и альтернативы пауза точки усиливает противопоставление между содержанием элемента в главной части и парцеллята и сильно подчеркивает возможость выбора между двумя вариантами.

Среди отношений, выступающих только в русском материале между сказуемыми-членами ряда имеются²:

- $\quad$ отношения одновременности, указывающие на то, что действия протекают одновременно, например:

Она заставила его фотографировать себя. Валялась на их алом покрывале с серпом и молотом, в черных трико, в свитере и в лисице на шее. Хохотала и плакала (Medvedeva).

- $\quad$ отношения последовательности, указывающие на этапное протекание действий, например:

Глеб помолчал, обдумыввая все, что усльшиал. Потом сказал: (Granovskij)

- $\quad$ отношения следствия, указывающие на результат действия:

- Bы, спартанцы, отчаянно смель и тупо упрямы. И кончите плохо. Но тыл можешь остаться здесь, со мной? (Efremov)

\section{2. Парцелляция сложного предложения}

Парцелляция сложного предложения - это явление довольно спорное и неоднозначное, особенно в случае сложных структур с бессоюзной и сочинительной связью, так как не всегда можно точно разграничить парцеллированные высказывания и сложные синтаксические целые. Парцеллированные сложноподчиненные предложения не доставляют таких трудностей, так как их придаточные являются синтаксически несамостоятельными и их зависимое положение при расчленении позволяет считать их парцеллятами, а не фрагментами сложного синтаксического целого [Dobryčeva 2012].

В описываемых языках парцелляции подвергаются как сложносочиненные, так и сложноподчиненные конструкции:

a) парцелляция сложносочиненных предложений

В парцеллированных сложносочиненных предложениях между главной и парцеллируемой частями имеются следующие семантические отношения, которые выражаются сочинительными союзами в начале парцеллята:

- соединительные, выражаемые союзом $u / i$, например:

2 Причиной отсутствия таких отношений в польском материале может быть факт, что в польском языке два сказуемых, соединенных на основе сочинения, не рассматриваются как сказуемые-члены ряда, а образуют сложносочиненное предложение [Urbańczyk 1978]. 
- Мне нужна одна вещь. И только ты можешь ее раздобыть (Granovskij). Ta pani kiedyś przyszła do mnie. I przyniosta mi list od swojego krewnego (Wiśniewski).

- $\quad$ противительные, выражаемые союзом нo/ale, например:

Музей еще не готов. Но замечательные экспонаты доставлены сюда со всего мира (Il'f, Petrov).

Z siostrą umówiony byłem, że jej mąż, gdy podrosnę, na wspólnika mnie weźmie. Ale zamordowali go trzy lata temu (Pilipiuk).

- разделительные (альтернатива), выражаемые союзами или; albo/lub, например:

Но неизвестно, чем все это могло кончиться. Он мог и баян «об землю вдарить», и пустить в тебя «что под руку попало». Или мог заплакать: Дочурочка, дорогенькая! (Gurčenko)

Prawdziwe listy, które można także po prostu spalić. Albo je po wielu latach odkryć na nowo (Wiśniewski).

Части сложносочиненных предложений, начинающиеся союзами $u / i$, нo/ale, uлu/albo не являются необходимыми. Благодаря парцелляции их появление кажется неожиданным, что позволяет выделить и подчеркнуть их содержание. Такое выделение одновременно облегчает сложную синтаксическую конструкцию.

б) парцелляция сложноподчиненных предложений

Среди парцеллированных сложноподчиненных предложений имеются:

- $\quad$ интенсиональные (изъяснительные), т.е. такие, в которых придаточная часть является необходимой для пополнения содержания глаголов, имеющихся в главной части [Grzegorczykowa 1999]. Это наиболее тесно связанные структуры среди сложных предложений, так как без придаточной части значение главной, а именно глагола является неполным [Grzegorczykowa 1999]. Факт обязательности придаточной части подтверждают парцеллированные конструкции, в которых в главной части всегда имеется придаточная часть, а в отдельную самостоятельную фразу выделяются добавочные придаточные, например:

Они пили вино, и Женщина плакала. Говорила, что в жизни у нее ничего не получилось, что никем она не стала, кем мечтала. Что это крах какойmo (Medvedeva).

Czut szóstym zmystem, że bandyci odeszli, lecz wiedziat, że nie może zaufać intuicji. Że zbytnia pewność siebie może go kosztować życie (Pilipiuk).

- $\quad$ с определительной придаточной частью, т.е. с присубстантивными придаточными, относящимися к подлежащему или дополнению в главной части [Grzegorczykowa 1999], напр.: 
Помешала ему быть с сыном и с таким тоненьким Критиком из Ленинграда. Который прекрасно говорит по-французски, у которого такие тонкие запястья, такие голубо-серые глаза, большие мягкие губы и тоненькие лопатки, в которые папа уткнул бы лицо, прижал бы щееку к одной лопатке, как к безопасному лезвию, и водил бы рукой по его ребрам, как по тонким черным клавишам (Medvedeva).

Dawaj nogę, gdyż nie ręczę za swój gniew. Który jest wielki, a będzie jeszcze większy (Masłowska).

Теперь эта подлая, парализующая волю мысль жила в его голове постоянно, не давала спать, набираться сил, мешала думать о чем-то другом отвлеченном или просто нейтральном. Безногий, с перебитой рукой - кому он нужен, кроме бедной его, исхудавщей и постаревщей матери, которой разрешили быть с ним, в палате?! Которая ухаживает за ним, как за малым и беспомощным ребенком: кормит с ложки и выносит за ним судно (Barabašov).

Wertując $w$ pamięci swój życiorys, zdat sobie $w$ tym momencie sprawę, że zatrzymywat się na dtużej wytacznie przy kobietach, z którymi chciat rozmawiać. I które mialy coś do powiedzenia (Wiśniewski).

Парцеллированные определительные придаточные наблюдаются в двух типах конструкций. В предложениях, в которых в главной части нет придаточной, парцелляты содержат характеристику подлежащего или дополнения имеющегося в базовой части. Парцеллят может быть также следующим придаточным и тогда в нем конкретизируется и расширяется значение придаточной части в главном предложении.

- экстенсиональные (обстоятельственные), которые составляют семантически очень разнообразную группу [Polański 1967]. Придаточные части выполняют функцию распространения главной части, если в ней нет обстоятельсва, или могут уточнять обстоятельства, имеющиеся в главной части. Между придаточными парцеллированными частями и главным предложением наблюдаются следующие семантические отношения:

- причины, например:

А Галя действительно была подкидышем, и даже фамилию ей в детском доме дали: Четвертак. Потому что меньше всех ростом вышла, в четверть меньше (Vasil'ev).

Dat ataman Bajda prawo: za jednego Kozaka wszyscy murem wystapia. Bo w jedności sila! (Pilipiuk)

- цели, например:

Только человек в пролетарской кепке, обожаюший Фердинанда Селина, не убежал. Сел с ними в такси, между ними сел. Чтобы Женщина не дергалась и не била опять Писателя (Medvedeva).

Potem zadzwonita do swojej matki. Rozmawiaty prawie dwie godziny. To znaczy, głównie matka mówiła. Potrzebowała tego. Aby się utwierdzić (Wiśniewski). 
Парцеллированные сложносочиненные и сложноподчиненные предложения являются коммуникативными (речевыми) вариантами непарцеллированных [Vannikov 1979]. Выделенные точкой в самостоятельные фразы части сложносочиненных предложений, начинающиеся союзами но/ale, pусским $u$, а также или, в непарцеллированной версии от главной части отделялись бы запятой. В польских примерах с союзами $i$ и albo в непарцеллированных вариантах не ставится запятая ${ }^{3}$.

Непарцеллированные придаточные части сложноподчиненных предложений, начинающиеся словами что, который, чтобы, nотому что и że, który, $a b y, b o$, отделяются от главной части запятой ${ }^{4}$.

Парцелляция как прием экспрессивного синтаксиса употребляется в русских и польских конструкциях разного типа. В простых предложениях в самостоятельные фразы выделяются повторы членов, имеющихся в базовой части, второстепенные члены предложения, отсутствующие в главной части, а также однородные члены, образующие ряды с соответствующими членами в базовой части. В последних конструкциях парцелляты связываются с членами ряда в главной части посредством внутрирядных отношений пояснения, перечисления, градации, противительности, альтернативы, а в случае русских сказуемых - одновременности, последовательности и следствия.

В сложных предложениях коммуникативную автономность могут приобретать части сложносочиненных предложений и придаточные сложноподчиненных. Между частями парцеллированных сложносочиненных конструкций имеются семантические отношения, выражаемые сочинительными союзами в начале парцеллята. Так, соединительные отношения передаются посредством союза $u / i$, противительные нo/ale и разделительные или/albo. В сложноподчиненных высказываниях парцелляции подвергаются придаточные интенсиональных, определительных и экстенсиональных предложений.

Главной функцией парцелляции является смысловое усиление и экспрессивное выделение определенной части текста. Выделенный элемент становится самым важным фрагментом высказывания и на него обращается особое внимание читателя. Парцелляты являются также актуализаторами содержания членов или целого базового предложения. В сложных высказываниях этот синтаксический прием употребляется тоже с целью удобного

3 http://old-rozental.ru/punctuatio.php?sid=133\#pp133, режим доступа 6.08.2019; http://www.rosental-book.ru/punct_xxvii.html, режим доступа 6.08.2019; https://sjp.pwn. pl/zasady/371-90-D-2-Zdania-wspolrzedne-polaczone-spojnikami-lacznymi-rozlacznymiwylaczajacymi;629785, режим доступа 1.09.2018.

4 http://www.rosental-book.ru/punct_xxviii.html, режим доступа 6.08.2019; https://sjp. pwn.pl/zasady/363-90-A-2-Wyrazy-wprowadzajace-zdanie-podrzedne;629774, режим доступа 12.09.2018. 
представления длинных текстов, так как разделенные на интонационно самостоятельные фразы сложные по структуре, семантике и синтаксическим связям предложения легче воспринимаются читающим.

\section{Литература}

\section{На русском языке}

Ârceva V.N. (ed.), 1990, Bol'šoj ènciklopedičeskij slovar'. Âzykoznanie, Moskva: Sovetskaâ ènciklopediâ.

Babajceva V.V., 2000, Âvleniâ perehodnosti v grammatike russkogo âzyka, Moskva: Drofa. Dobryčeva A.A., 2012, Parcellâciâ v proze S. Dovlatova: ot predloženiâ k tekstu. Dissertaciâ na soiskanie učenoj stepeni k.f.n., Vladivostok.

Kopnina G.A., 2008, Parcellâciâ, http://library.krasu.ru/ft/ft/_articles/0070223.pdf; 3.08.2008.

Rozental' D.È., Telenkova M.A., 2001, Slovar'-spravočnik lingvističeskih terminov, Moskva: Astrel' AST.

Skovorodnikov A.P., 1980, O funkciâh parcellâcii v sovremennom russkom literaturnom âzyke, Russkij âzyk v škole, 5, pp. 86-91.

Vannikov U.V., 1979, Sintaksis reči i sintaksičeskie osobennosti russkoj reči, Moskva: Russkij âzyk.

\section{На польском языке}

Angełowa I., 1985, Charakterystyka interpunkcji polskiej w świetle normy i praktyki, Wrocław-Warszawa-Kraków-Gdańsk-Łódź: Wydawnictwo Polskiej Akademii Nauk.

Gołąb Z., Heinz A., Polański K., 1968, Słownik terminologii językoznawczej, Warszawa: PWN.

Grzegorczykowa R., 1999, Wykłady z polskiej składni, Warszawa: Wydawnictwo Naukowe PWN.

Grzesiuk A., 1995, Składnia wypowiedzi emocjonalnych, Lublin: Wydawnictwo UMCS. Jodłowski S., 1932, O nowej modzie literackiej w interpunkcji, Język Polski, XVII, 1.

Komorowska E., 2001, Leksykalno-semantyczne wyktadniki parentezy postpozycyjnej w języku polskim i rosyjskim, Szczecin: Wydawnictwo Naukowe Uniwersytetu Szczecińskiego.

Polański K., 1967, Składnia zdania złożonego w języku górnołużyckim, Wrocław-WarszawaKraków: Wydawnictwo Polskiej Akademii Nauk.

Polański K. (red.), 1993, Encyklopedia językoznawstwa ogólnego, Wrocław: Zakład Narodowy im. Ossolińskich.

Pospiszylowa A., 1973, Wyodrębnienie dowolnej części zdania w oddzielne wypowiedzenie, Język Polski, LIII, 5.

Saloni Z., 1971, Błędy językowe w pracach pisemnych uczniów liceum ogólnokształcacego. Próba analizy językoznawczej, Warszawa: Państwowe Zakłady Wydawnictw Szkolnych. Saloni Z., 1977, W sprawie interpunkcyjnego usamodzielnienia członu zdaniowego, Język Polski, LVII, 4.

Urbańczyk S., 1978, Encyklopedia wiedzy o języku polskim, Wrocław: Ossolineum. 